\title{
Intestinal Parasitic Load in Healthy Individuals
}

\author{
Yogendra Singh ${ }^{1 *}$, Astha Gupta ${ }^{1}$ and Pankaj Kumar Singh ${ }^{2}$ \\ ${ }^{1}$ Demonstrator Department of Microbiology Government College, Jalaun, India \\ ${ }^{2}$ Department of Medicine, Government State Autonomous Medical College, Bahraich, \\ $U P$, India
}

*Corresponding author

\section{Keywords \\ Entamoeba \\ histolytica, \\ Hygiene, Intestinal parasites, Sanitation \\ Article Info \\ Accepted: \\ 04 August 2019 \\ Available Online: \\ 10 September 2019}

\section{A B S T R A C T}

Intestinal parasitic infections are worldwide endemic and are a major public health problem of concern. The incidence is high in developing countries like India probably due to contaminated food and lack of knowledge. The stool samples from healthy individuals in slum communities of Ghaziabad were collected and examined Macroscopic for the presence adult worms or their body segments and microscopic examination both saline and iodine mounts after Formol-ether concentration technique for presence of cyst and eggs. The total numbers of 100 samples were examined for parasitic finding among them 40 were found to be positive for parasitic findings. In which 26(60\%) were males and $14(35 \%)$ females, age group 21-30 years were the most common. The finding of the pathogenic case were $28(70 \%)$ and non-pathogenic 12(30\%) findings among pathogenic findings the most common were Entamoeba histolytica 10(25\%) followed by Hymenolepis nana 8(20\%), Taenia species 7(17.5\%). Dual positive were also found in 4 persons of Entamoeba histolytica + Hymenolepis nana and Taenia solium + Entamoeba histolytica. The incidence of infestation was $40 \%$ and it is high suggesting for proper hygienic and avoids contaminated food consumption.

\section{Introduction}

Parasitic infections, caused by intestinal helminthes and protozoan are among the most prevalent infections in humans in developing countries. Nematodes (roundworms), cestodes (tapeworms) and trematodes (flatworms) are among the most common helminthes that inhabit the human gut. ${ }^{(1)}$ Intestinal parasites establish significant medical issues, particularly in the tropical and subtropical districts. In creating nations, it is assessed that some 3.5 billion individuals are influenced, and that 450 million are sick because of these diseases, mainly in children. ${ }^{(2)}$ The reason behind the high prevalence of these infestations is closely correlated to poverty poor environmental hygiene and impoverished health services. ${ }^{(3)}$

Intestinal parasite infestations are more frequent among school age children, and they tend to occur in high intensity in this age group. $^{(4)}$ Like other developing nations, intestinal parasitic infections are a noteworthy medical issue in India. In previous studies 
conducted in low-socio economic areas in and around Chandigarh, reported the prevalence of intestinal parasitic diseases ranging from 14.6$19.3 \% .^{(5,6)}$ Current study of India in rural valley of Kashmir, has been reported that at least one intestinal helminthes was found in $71.2 \%$ of the sampled population. The prevalence of Ascaris lumbricoides was highest (68.3\%), followed by Trichuris trichiura (27.9\%), Enterobius vermicularis $(12.7 \%)$ and Taenia saginata $(4.6 \%) .{ }^{(7)}$ Therefore, it is important to monitor the problem time to time and tackle it in the interest of public health.

\section{Materials and Methods}

This study was conducted in the Department of Microbiology Santosh Medical College, Ghaziabad in year 2017. 100 Fresh stool samples were collected from healthy individuals in slum communities of Ghaziabad.

\section{Inclusion criteria}

Normal healthy individuals, from different age groups and from different slum areas and of low socioeconomic communities in NCR region.

\section{Exclusion criteria}

Immunocompromised individuals

Individuals being treated by anti- parasitic drugs.

Individuals suffering from diarrhoea.

\section{Specimen collection}

Fresh Stool samples were collected from healthy individuals in slum communities of Ghaziabad. These samples were collected in wide mouth containers without any preservative then labelled with name, age and sex.

\section{Specimen examination}

The stool samples were subjected to gross and microscopic examination. Naked eye examination was done for intestinal worms and segment of Taenia species and stored at $4^{\circ} \mathrm{C}$ and sent to laboratory immediately. In macroscopic examination we observe the color, consistency, odour, presence of blood and mucus and adult worms and in Microscopic observation Charcot-Leyden crystals, Cellular exudates such as pus cells, RBC's and macrophages, Intestinal protozoa such as trophozoites and cysts and Helminthic eggs.

\section{Results and Discussion}

A total of 100 stool samples were included in the study of which $64(64 \%)$ were males and $36(36 \%)$ were females. All the samples were from the age group between 0 to 60 years. Of the total 100 stool sample examined only 40 (40\%) samples had parasitic infestation while the remaining $60(60 \%)$ samples were negative. The total 40 positive stool findings of some parasitic infection, protozoan are formed $(62.5 \%)$ of the total parasitic infection while $(37.5 \%)$ was the helminthic. In table no. 1 shows the prevalence of intestinal parasitic infections was found to be higher in males $(65 \%)$ than females (35\%). In table 2 shows the higher result of $16(40 \%)$ stool samples that had parasitic infestation was in the group of the under 21-30 years age limit while only one sample $(2.5 \%)$ in the group of the under 0 5 years age limit. In table 3 shows out of 40 positive samples that had positive stool findings for ova/cyst $26(65 \%)$ were in males and $14(35 \%)$ in females. The Maximum numbers of ova $4(15.38 \%)$ and cyst 7 (26.92\%) were found in males in the age group of 21-30 years while only one ova 
$1(3.8 \%)$ was in the $41-50$ years age limit and only one $(3.8 \%)$ cyst was found in the $0-5$ years of age limit. There was no parasitic (ova/cyst) infection in the age group of 610years. Maximum number of ova $2(14.28 \%)$ and cyst $3(21.42 \%)$ were found in females in the age group of 21-30years while only one $(7.14 \%))$ ova was found in females in the 3140years age limit and one $(7.14 \%)$ cyst in the 11-20 years age limit. A total number of ova 8 $(30.76 \%)$ and cyst $18(69.32 \%)$ were found in males while the total number of ova 4 $(28.57 \%)$ and cyst $10(71.42 \%)$ were found in females. In table 4 among the parasites found in the stool samples Entamoeba histolytica was the most prevalent species (25\%) followed by Hymenolepis nana (20\%), Taenia species (17.5\%) and Giardia lamblia (7.5\%). Among the non-pathogenic findings Entamoeba coli was higher $(17.5 \%)$ than Endolimax nana (12.5\%). In table 5 shows that only four cases we found double intestinal parasitic infection. Entamoeba histolytica was common parasite in four cases of double intestinal parasitic infection while Hymenolepis nana and Taenia solium were common in two cases of double parasitic infection.

Stool examination for parasitic ova, cysts, trophozoite and larvae remains the gold standard for laboratory diagnosis for intestinal parasitic infection $^{(8)}$ Lack of knowledge of prevalence of parasites in a particular geographic area may lead to misdiagnosis and other inflammatory bowel diseases ${ }^{(9)}$. The results showed the total infection with intestinal parasites (40\%) is high because there are many people in slum areas who suffering from parasitic infections due to unhygienic lifestyle, lack of health education, increasing of vectors and malnutrition states in addition to using of river water directly for drinking and washing. The outcomes demonstrated the all-out disease with intestinal parasites. Concentrates outside India have announced a parasitic incidence of 25 to $70 \%{ }^{(10)}$. In our study we found $40 \%$ incidence rate. All the samples were from the age group between 0 to 60 years. The higher positive rate of $16(40 \%)$ stool samples that had parasitic infestation was in the group of the under 21-30 years age limit while only one sample $(2.5 \%)$ in the group of the under 0-5 years age limit. The high incidence of intestinal parasitic infections (IPI) in males in the age group of $21-30$ years is probably due to crawling habits which increases their contact with soil and accidental transfer of parasites there from, to the mouth. Traditionally, females of the same age group 21-30 years are more prone to be restricted indoors amongst the study populations. This probably explains the lower incidence of IPI in this age group (among girls) as compared to the age group 11-20yrs, when the girl child is made to perform all kinds of household as well as outside chores particularly in the rural population ${ }^{(11)}$.

Our study showed, the incidence of intestinal parasitic infections was higher in males $65 \%$ than females $35 \%$. Studies from other countries reported differences in the prevalence of infections between males and females. $^{(12)}$

In this study the protozal infection was $62.5 \%$ whereas the other study rate of helminthic infection was $37.5 \%$ and Sehegal et al., found that $81.2 \%$ prevalence rate of protozoal infection whereas $18.8 \%$. By helminthes. ${ }^{(13)}$ In a recent study, it was found that E. histolytica was the commonest parasite $(43.8 \%)$ followed by $C$. parvum $(29.8 \%)$ and $G$. lamblia $(10.53 \%)^{(14) .}$ In Marothi and Singh's study, $E$. histolytica was the commonest parasitic protozoa $(10.5 \%)$ followed by $G$. lamblia (3.9\%), and among helminthes, $A$. lumbricoides was the commonest $(2.8 \%)$ (135). Our study showed that the most common intestinal parasite was Entamoeba histolytica $(25 \%)$. 
Table.1 Sex distribution of positive parasites

\begin{tabular}{|l|c|c|}
\hline Sex & No of Positive for parasites & Percentage \\
\hline Male & 26 & $65 \%$ \\
\hline Female & 14 & $35 \%$ \\
\hline Total & 40 & $100 \%$ \\
\hline
\end{tabular}

Table.2 Age distribution of parasitic infections

\begin{tabular}{|l|c|c|}
\hline Age (years) & No. of Positive for Parasites & Percentage (\%) \\
\hline $\mathbf{0 - 5}$ & 1 & $2.5 \%$ \\
\hline $\mathbf{6 - 1 0}$ & 1 & $2.5 \%$ \\
\hline $\mathbf{1 1 - 2 0}$ & 4 & $10 \%$ \\
\hline $\mathbf{2 1 - 3 0}$ & 16 & $40 \%$ \\
\hline $\mathbf{3 1 - 4 0}$ & 12 & $30 \%$ \\
\hline $\mathbf{4 1 - 5 0}$ & 4 & $10 \%$ \\
\hline $\mathbf{5 1 - 6 0}$ & 2 & $5 \%$ \\
\hline Total & 40 & 100 \\
\hline
\end{tabular}

Table.3 Distribution of ova/cyst in relation to age and sex

\begin{tabular}{|l|c|c|c|c|c|c|c|c|}
\hline \multirow{2}{*}{$\begin{array}{l}\text { Age } \\
\text { (years) }\end{array}$} & \multicolumn{5}{|c|}{ Male (N=26) } & \multicolumn{4}{|c|}{ Female (N=14) } \\
\cline { 2 - 9 } & ova & $(\%)$ & Cyst & $(\%)$ & ova & $(\%)$ & Cyst & $(\%)$ \\
\hline $\mathbf{0 - 5}$ & - & - & 1 & 3.84 & - & - & - & - \\
\hline $\mathbf{6 - 1 0}$ & - & - & - & - & - & - & 1 & 7.14 \\
\hline $\mathbf{1 1 - 2 0}$ & - & - & 3 & 11.53 & - & - & 1 & 7.14 \\
\hline $\mathbf{2 1 - 3 0}$ & 4 & 15.38 & 7 & 26.92 & 2 & 14.28 & 3 & 21.42 \\
\hline $\mathbf{3 1 - 4 0}$ & 3 & 11.53 & 5 & 19.29 & 1 & 7.14 & 3 & 21.42 \\
\hline $\mathbf{4 1 - 5 0}$ & 1 & 3.84 & - & - & 1 & 7.14 & 2 & 14.28 \\
\hline $\mathbf{5 1 - 6 0}$ & - & - & 2 & 7.69 & - & - & - & - \\
\hline Total & 8 & 30.76 & 18 & 69.32 & 4 & 28.57 & 10 & 71.42 \\
\hline
\end{tabular}

Table.4 Parasite distribution in stool specimens $(\mathrm{N}=40)$

\begin{tabular}{|l|l|l|l|}
\hline \multirow{2}{*}{ Pathogenic Cyst/ova } & Parasites & Numbers & Percentage (\%) \\
\hline & Entamoeba histolytica & 10 & $25 \%$ \\
\cline { 2 - 4 } & Giardia lamblia & 3 & $7.5 \%$ \\
\cline { 2 - 4 } & Hymenolepis nana & 8 & $20 \%$ \\
\cline { 2 - 4 } & Taenia species & 7 & $17.5 \%$ \\
\hline \multirow{2}{*}{$\begin{array}{l}\text { Non-pathogenic } \\
\text { cyst/ova }\end{array}$} & Entamoeba coli & 7 & $17.5 \%$ \\
\hline Total & Endolimax nana & 5 & $12.5 \%$ \\
\hline
\end{tabular}


Table.5 Distribution of double parasitic infection

\begin{tabular}{|l|c|c|}
\hline Parasites & $\begin{array}{c}\text { Individuals with Double } \\
\text { Intestinal Parasitic Infection }\end{array}$ & $\begin{array}{c}\text { Percentage with Double } \\
\text { Intestinal Parasitic Infection }\end{array}$ \\
\hline $\begin{array}{l}\text { Entamoeba histolytica } \\
\text { Hymenolepis nana }\end{array}$ & 2 & $5 \%$ \\
\hline $\begin{array}{l}\text { Taenia species+ Entamoeba } \\
\text { histolytica }\end{array}$ & 2 & $5 \%$ \\
\hline Total & 4 & $10 \%$ \\
\hline
\end{tabular}

The prevalence of amoebiasis occurs in tropical countries where the warm wet climate provides environmental conditions followed by Hymenolepis nana (20\%), Taenia solium (17.5\%) and Giardia lamblia (7.5\%0). Our study reported $70 \%$ pathogenic ova/ cysts and $30 \%$ were non-pathogenic intestinal parasites in which $62.5 \%$ protozoan's formed of the total parasitic infestation while $37.5 \%$ was the helminthic infestation. Study by Randhir Kumar et al., showed prevalence of intestinal infections was higher in protozoa with nonpathogenic spp. $(62.5 \%)$ than the helminthic (37.5\%) E. coli, E. nana, T. hominis are considered nonpathogenic parasites in human, they worldwide distribution and their cysts contaminate food and drinking water then infect human. Detection of these nonpathogenic parasites in human would suggest ingestion of contaminated water or food and may indicate possible exposure to pathogenic organisms (15). Our study showed the prevalence of the intestinal parasitic infection was higher (40\%) and Entamoeba histolytica was the most prevalent species and Hamad et al., ${ }^{(16)}$ reported $30 \%$ intestinal parasitic infection. In slum areas, ignorance, unhealthy socio-cultural and religious practices, lack of basic public amenities, poor sanitation, poverty and inadequate access to health care are major predisposing factors to intestinal parasitic infections (17). This study observed the above factors in the slum community. The houses of in these areas lack adequate toilet facility. There is complete absence of potable water; peoples obtain their water from nearby stream that might have been contaminated with fecal matter. Evidently, students defecate indiscriminately in the bushes around the school premises as observed with fecal littering, which were likely to contain ova and/or cyst of parasites.

The randomly examination for intestinal parasites is $40 \%$ were positive in Ghaziabad district in Uttar Pradesh because of it being the industrial city, low literacy rate, improper drinking water supply, low socioeconomic status and poor sanitation in the rural areas Entamoeba histolytica and Hymenolepis nana most common parasites infestation which reflects the habits of defecation in open places and lack of awareness among people.

\section{References}

1. Rashidul $\mathrm{H}$ et al., Human Intestinal Parasites. 2007; 25(4): 387-391.

2. Abdelsafi A Gabbad, Mohammed A Elawad Prevalence of Intestinal Parasite Infection in Primary School Children in Elengaz Area, Khartoum, Sudan Academic Research International. 2014; 5(2): 86-92.

3. Rashid, M. K., Joshi, M., Joshi, H. S. and Fatemi, K. Prevalence of Intestinal Parasites among School Going Children in Bareilly District. NJIRM. 2011; 2(1): 2230-9969.

4. Sehga, R., Gogulamudi, V. R., Jaco, J. V. and Atluri, V. Prevalence of intestinal parasitic infections among 
school children and pregnant women in a low socio-economic area, Chandigarh, North India. RIF. 2010; 1(2): 100-103.

5. Bansal, D., Sehgal, R., Bhatti, H. S., Shrivastava, S. K., Khurana, S., Mahajan, R. C., and Malla, N. Intestinal parasites and intra familial incidence in a low socio-economic area of Chandigarh (North India). Nepal Med Coll J. 2004; 6(4): 28-31.

6. Khurana, S., Aggarwal, A., and Malla, N. Comparative analysis of intestinal parasitic infections in slum, rural and urban populations in and around union Territory, Chandigarh. J Commun Dis.2005; 37(5): 239-243.

7. Wani, S. A., Ahmad, F., Zargar, S. A., Ahmad, Z., Ahmad, P., and Tak, H. (2007). Prevalence of intestinal parasites and associated risk factors among schoolchildren in Srinagar City, Kashmir, India. J Parasitol. 2007; 93(7): 1541-1543.

8. WHO. Basic laboratory methods in medical parasitology. Geneva, WHO: 1991.

9. Dickson R, Awasthi S, Demellweek C, Williamson P. Anthelmintic drugs for treating worms in children: effects on growth and cognitive performance. Cochrane Database Syst Rev 2003; CD000371.

10. Bandy DA, Kan SP, Rose R. Age related prevalence intensity and frequency distribution of gastrointestinal helminth infection in urban slum children. 1988; 82: 289-294.

11. Randhir Kumar, Priyanka Paul Biswas, Tarannum Yasmin, Aninda Sen,
Udayan Ganguly (2014); Prevalence Of Intestinal Parasitic Infections In Patients Attending A Tertiary Care Hospital In Eastern Bihar, Journal of Evolution of Medical and Dental Sciences 2014; 3(24): 6740-46.

12. Jayalakshmi S, Dharanidevi S. The Prevalence of Intestinal Parasitic Infections in a Tertiary Care Hospital in Southern India-A Retrospective Study. Int J Curr Microbiol App Sci. 2016; 5(10): 718-23.

13. Sehgal R, Reddy GV, Verweij JJ, Rao AV. Prevalence of intestinal parasitic infections among school children and pregnant women in a low socioeconomic area, Chandigarh, North India. RIF 2010; 1: 100-103.

14. N. Srihari, T. S. Kumudini, J. Mariraj, and S. Krishna, "The prevalence of intestinal parasitic infection in a tertiary care hospital - a retrospective study." Journal of Pharmaceutical and Biomedical Sciences 2011; 12: 1-4.

15. Y. Marothi and B. Singh et al., "Prevalence of intestinal parasites at Ujjain, Madhya Pradesh, India: fiveyear study." African Journal of Microbiology Research 2011; 5: 27112714.

16. Naish S, McCarthy J, Williams GM. Prevalence, intensity and risk factors for soil-transmitted helminthic infection Acta Trop. 2007; 91: 177-187.

17. Hamad, NR. and Ramzy, IA et al., Epidemiology of Entamoeba histolytica among children $J$ Research in Biology. 2012; 1: 057-062.

\section{How to cite this article:}

Yogendra Singh, Astha Gupta and Pankaj Kumar Singh. 2019. Intestinal Parasitic Load in Healthy Individuals. Int.J.Curr.Microbiol.App.Sci. 8(09): 68-73. doi: https://doi.org/10.20546/ijcmas.2019.809.010 